\title{
Synthetic route optimization of Sumepirin antiepileptic drug candidate
}

\author{
M.S. Dzyurkevich, N. V. Shtyrlin, Y. G. Shtyrlin ${ }^{*}$ \\ Kazan (Volga region) Federal University, \\ 420008, Kremlevskaya str. 18, Kazan, Russia \\ *email:yurii.shtyrlin@kpfu.ru
}

Abstract. In this work we describe the transformation of synthetic route of the antiepileptic drug candidate Sumepirin starting from discovery stage. Initial method included six step process requiring two steps of purification using colon chromatography and has poor overall yield of target compound. The process developed is convenient, scalable, technological and meet the most of conditions of green chemistry. The overall yield was increased up to $62.5 \%$ in four steps without colon chromatography purification which allows to obtain the target compound with purity of $99.5+\%$ which is especially important for the active ingredient.

Keywords: pyridoxine; synthetic route optimization; scale-up; purification; antiepileptic drug; technology

Received: 15.10.2020. Accepted: 09.12.2020. Published:30.12.2020.

(c) M. S. Dzyurkevich, N. V. Shtyrlin, Y. G. Shtyrlin, 2020

\section{Introduction}

The social and medical significance of epilepsy is determined by its high prevalence. Epilepsy is one of the most common chronic diseases of the nervous system in the world, which affects both children and adults. $5 \%$ of the population suffers at least one epileptic seizure during their lifetime. In $70 \%$ of cases, epilepsy debuts in childhood and adolescence. Patients with epilepsy may have mental problems including personality changes specific to the disease associated with a mnesticintellectual defect, affective disorders and so-called epileptic psychoses. According to the WHO, about 50 million people suffer from epilepsy, which is about $0.5-1 \%$ of the world's population (https://www. who.int/news-room/fact-sheets/detail/ epilepsy). Approximately 5 million new cases are diagnosed worldwide each year.
Moreover, $30 \%$ of patients with epilepsy are pharmacoresistant [1]. On the other hand, existing antiepileptic drugs have a lot of side effects including ataxia, decreased mental ability, drowsiness, dizziness, digestive disorders, etc. [2]. Development of effective and safe drugs may significantly improve the quality of life of patients suffering from epilepsy.

Sumepirin $\mathbf{1}$ is a novel antiepileptic drug candidate developed in the Scientific and Educational Center of Pharmaceutics of the Kazan Federal University and having pronounced antiseizure effect and improved safety profile. This compound is pyridoxine-based molecule with residue of methanesulfonic acid in the $6^{\text {th }}$ position of pyridoxine ring (Fig. 1).

It has successfully passed preclinical studies in the framework of State pro- 
<smiles>Cc1nc(CS(=O)(=O)O[Na])c(CO)c(CO)c1O</smiles>

Sumepirin

(1)

Fig. 1. Structure of Sumepirin 1

gram of Russian Federation «Development of the Pharmaceutical and Medical Industry» and is planned to undergo the clinical trials. As Sumepirin entered preclinical studies stage an urgent need of the optimization of its method of synthesis arised. Preclinical phase involves study of chronical toxicity of a drug can- didate both in small (e.g. mice or rats) and large (rabbits) animals. The duration of these experiments depends on the expected duration of the course of the drug. Antiepileptic drugs are usually taken for an extended period of time: from months to years. That means that chronical toxicity should be studied at least for 6 month of everyday administration of a drug. During the discovery stage a general method of synthesis was used which allows preparation of diverse set of 6-substitued pyridoxine derivatives. This method is not suitable for large-scale synthesis as required at preclinical trials. This required the development of more convenient and scalable synthetic approach.

\section{Experimental}

Unless otherwise stated, chemicals are obtained from the commercial suppliers and were used without further purification. ${ }^{1} \mathrm{H}$ and ${ }^{13} \mathrm{C}$ NMR spectra were recorded on a "Bruker AVANCE 400" at operating frequencies of 400.13 and $100.62 \mathrm{MHz}$, respectively. Chemical shifts were measured with reference to the residual peak of the solvent (DMSO- $\mathrm{d}_{6},{ }^{1} \mathrm{H}, 2.50 \mathrm{ppm}$, ${ }^{13} \mathrm{C}, 39.52 \mathrm{ppm} ; \mathrm{CDCl}_{3},{ }^{16} \mathrm{H}, 7.26 \mathrm{ppm},{ }^{13} \mathrm{C}$, $77.16 \mathrm{ppm})$. Coupling constants (J) are given in Hertz (Hz). The following abbreviations are used to describe coupling: $s$ = singlet; $\mathrm{d}=$ doublet $\mathrm{t}$ = triplet. Melting points were determined using a Stanford Research Systems MPA-100 OptiMelt melting point apparatus and are uncorrected. For TLC analysis, silica gel plates from Sorbfil (Krasnodar, Russia) were used with UV light $(254 \mathrm{~nm})$ as a developing agent. Column chromatography was performed on silica gel (60-200 mesh) from Acros.

High-resolution mass spectroscopy mass spectra were obtained on a quad-

rupole time-of-flight ( $t$, qTOF) AB Sciex Triple TOF 5600 mass spectrometer using turbo-ion spray source (nebulizer gas nitrogen, positive ionization polarity, needle voltage $5500 \mathrm{~V}$ ). Recording of the spectra was performed in "TOF MS" mode with a collision energy of $10 \mathrm{eV}$, declustering potential of $100 \mathrm{eV}$ and resolution more than 30,000 full-width half-maximum. Samples with the analyte concentration $5 \mu \mathrm{mol} / \mathrm{L}$ were prepared by dissolving the test compounds in a mixture of methanol (HPLCUV Grade, LabScan) and water (LC-MS Grade, Panreac) in 1:1 ratio.

Compounds 3, 4, 5 and 6 were obtained according to published procedures [3-5] without any modifications, unless otherwise is stated.

I. Optimized method of synthesis of 6-(hydroxymethyl)-3,3,8-trimethyl-1,5-dihydro-[1,3] dioxepino[5,6-c] pyridin-9-ol (4). $143 \mathrm{~g}(684 \mathrm{mmol}) \mathrm{com}$ pound 3 is added to the 2-liter doublenecked round bottom flask equipped with 
magnetic stirring bar and a thermometer. Solution of $14 \mathrm{~g}$ (342 mmol) of sodium hydroxide in $342 \mathrm{ml}$ of distilled water and $120 \mathrm{ml}$ of freshly distilled formaldehyde solution (37\% wt., $1641 \mathrm{mmol}$, stabilized with $5 \%$ methanol) is added to the reaction vessel. Mixture is flushed with argon and reaction is carried out under inert atmosphere at $70{ }^{\circ} \mathrm{C}$ for about $5 \mathrm{~h}$. The reaction is controlled by TCL on silica (eluent $\mathrm{CHCl}_{3}: \mathrm{MeOH}=10: 1$ ) until the spot of starting material completely disappears. After reaction is finished, reaction mixture is cooled down to the room temperature and neutralized by the $1 \mathrm{M}$ solution of hydrochloric acid to the $\mathrm{pH}=6.5$. A seed of water-insoluble crystalline form of 4 $(10 \mathrm{mg})$ is added to the solution. Solution is then transferred into the 2-liter beaker and left overnight to achieve complete crystallization. The precipitate formed is filtered off, washed 3 times with the 100 $\mathrm{ml}$ of distilled water and dried to obtain $154 \mathrm{~g}$ (94\%) of compound 4 as pale yellow solid; m.p. $182-183^{\circ} \mathrm{C} .{ }^{1} \mathrm{H}$ NMR (DMSO$\mathrm{d}_{6}$ ), $\delta$, ppm: 1.41 (s, 6H), 2.33 (s, 3H), 4.42 $(\mathrm{s}, 2 \mathrm{H}), 4.80(\mathrm{~s}, 2 \mathrm{H}), 4.82(\mathrm{~s}, 2 \mathrm{H})$. Spectrum is in accordance with the previously published [4].

II. Synthesis of sodium (9-hydroxy3,3,8-trimethyl-1,5-dihyd ro- $[1,3]$ dioxepino[5,6-c]pyridin-6-yl)methanesulfonate (7) starting from 6-(chloromethyl)-3,3,8-trimethyl-1,5-dihydro-[1,3]dioxepino[5,6-c]pyridin-9-yl acetate (6). In the $100 \mathrm{ml}$ round bottom flask equipped with mechanical stirring bar a solution of $1.0 \mathrm{~g}(3.34 \mathrm{mmol})$ of compound $\mathbf{6}$ in $20 \mathrm{ml}$ of dichloromethane and solution of $0.8 \mathrm{~g}(6.67 \mathrm{mmol})$ of sodium sulfite in $30 \mathrm{ml}$ of water were added. $0.01 \mathrm{~g}$ $(0.03 \mathrm{mmol})$ of TBAB were added to the reaction mixture and the reaction was carried out at room temperature while vig- orous stirring for $10 \mathrm{~h}$. Then water layer is separated from the organic and water is removed under reduced pressure. Dry solid residue is extracted with $3 \times 100 \mathrm{ml}$ of hot isopropyl alcohol. Alcohol extract is evaporated until $30 \mathrm{ml}$ left and white precipitate formed is filtered off and washed with $10 \mathrm{ml}$ of cold isopropyl alcohol. After drying $0.66 \mathrm{~g} \mathrm{(61 \% )}$ of compound 7 was obtained as white solid; m.p. $197^{\circ} \mathrm{C}$ (decomp.). NMR ${ }^{1} \mathrm{H}(400 \mathrm{MHz}, \mathrm{DMSO}-$ $\left.\mathrm{d}_{6}\right), \delta$, ppm: $1.38\left(\mathrm{~s}, 6 \mathrm{H}, \mathrm{C}\left(\mathrm{CH}_{3}\right)_{2}\right), 2.30(\mathrm{~s}$, $\left.3 \mathrm{H}, \mathrm{CH}_{3}\right), 3.82\left(\mathrm{~s}, 2 \mathrm{H}, \mathrm{CH}_{2} \mathrm{~S}\right), 4.79(\mathrm{~s}, 2 \mathrm{H}$, $\left.\mathrm{CH}_{2}\right), 4.90\left(\mathrm{~s}, 2 \mathrm{H}, \mathrm{CH}_{2}\right) . \mathrm{NMR}{ }^{13} \mathrm{C}\left\{{ }^{1} \mathrm{H}\right\}$ $\left(100 \mathrm{MHz}, \mathrm{DMSO}-\mathrm{d}_{6}\right), \delta$, ppm: 19.28, 23.73, 57.47, 59.11, 60.97, 101.45, 132.07, 134.18, 140.97, 143.25, 146.78. HRMS-ESI: found $[M+H]^{+} 326.0667, \mathrm{C}_{12} \mathrm{H}_{16} \mathrm{NNaO}_{6} \mathrm{~S}$, calculated $[M+H]^{+} 326.0669$.

III. Synthesis of sodium (5-hydroxy-3,4-bis(hydroxymethyl)-6-methylpyridin-2-yl)methanesulfonate (1) starting from sodium (9-hydroxy3,3,8-trimethyl-1,5-dihydro- $[1,3]$ dioxepino[5,6-c]pyridin-6-yl)methanesulfonate (7). $0.66 \mathrm{~g}(2.03 \mathrm{mmol})$ of compound 7 is dissolved in $10 \mathrm{ml}$ concentrated hydrochloric acid. The solution was stirred for $1 \mathrm{~h}$ at room temperature. After this insoluble $\mathrm{NaCl}$ filtered off (solubility of $\mathrm{NaCl}$ in concentrated $\mathrm{HCl}$ solution is $0.1 \% \mathrm{wt}$.) and $40 \mathrm{ml}$ of isopropanol is added to the filtrate. After standing for 1 hour a crystalline precipitate is formed. The solid is filtered off, washed with $10 \mathrm{ml}$ of cold isopropanol and dried. Dry solid is dissolved in $15 \mathrm{ml}$ of distilled water and titrated with $0.1 \mathrm{M}$ $\mathrm{NaOH}$ solution until $\mathrm{pH}=7.2$. After drying $0.57 \mathrm{~g}(98 \%)$ of compound $\mathbf{1}$ was obtained as white solid; m.p. $265^{\circ} \mathrm{C}$ (decomp.). NMR ${ }^{1} \mathrm{H}\left(400 \mathrm{MHz}, \mathrm{DMSO}-\mathrm{d}_{6}\right), \delta$, ppm: $2.31\left(\mathrm{~s}, 3 \mathrm{H}, \mathrm{CH}_{3}\right), 4.04\left(\mathrm{~s}, 2 \mathrm{H}, \mathrm{CH}_{2}\right), 4.51$ $\left(\mathrm{d},{ }^{3} \mathrm{~J}_{\mathrm{HH}}=6.3 \mathrm{~Hz}, 2 \mathrm{H}, \mathrm{CH}_{2}\right), 4.78(\mathrm{~s}, 2 \mathrm{H}$, $\left.\mathrm{CH}_{2}\right), 5.17\left(\mathrm{t},{ }^{3} \mathrm{JHH}_{\mathrm{HH}}=6.3 \mathrm{~Hz}, 1 \mathrm{H}, \mathrm{OH}\right) . \mathrm{NMR}$ 
${ }^{13} \mathrm{C}\left\{{ }^{1} \mathrm{H}\right\}\left(100 \mathrm{MHz}, \mathrm{DMSO}-\mathrm{d}_{6}\right), \delta, \mathrm{ppm}:$ $19.33,56.80,57.16,57.21,132.07,132.74$, 143.31, 145.04, 148.94. HRMS-ESI: found $[\mathrm{M}+\mathrm{H}]^{+} 286.0354, \mathrm{C}_{9} \mathrm{H}_{12} \mathrm{NNaO}_{6} \mathrm{~S}$, calculated $[M+H]^{+} 286.0356$.

IV. Modified synthesis of (9-acetoxy-3,3,8-trimethyl-1,5-dihydro-[1,3] dioxepino [5,6-c]pyridin-6-yl)methyl acetate (10). 1-liter double-necked round bottom flask equipped with magnetic stirring bar and effective reflux condenser is charged with $90 \mathrm{~g}$ (376 mmol) of compound 4, $55 \mathrm{ml}$ of triethylamine (395 $\mathrm{mmol}$ ) and $400 \mathrm{ml}$ of dichloromethane. $28 \mathrm{ml}$ of acetyl chloride $(395 \mathrm{mmol})$ in 100 $\mathrm{ml}$ of dichloromethane is charged into drop funnel which is then attached to the flask. Acetyl chloride is added dropwise to the reaction mixture while stirring to maintain slow boiling. After whole amount is added reaction mixture is stirred for additional $0.5 \mathrm{~h}$ and then extracted with $3 \times 200 \mathrm{ml}$ of distilled water and washed with brine. Organic layer is separated, dried over anhydrous sodium sulfate and evaporated. Residue is dried under vacuum to obtain $119 \mathrm{~g}$ (98\%) of $\mathbf{1 0}$ as viscous liquid of yellow to light brown color which may crystallize upon long standing. NMR ${ }^{1} \mathrm{H}$ (400 MHz, DMSO-d d $_{6}$, $\delta$, ppm: 1.48 (s, 6H, $\left.\mathrm{CH}_{3}\right), 2.09$ (s, 3H, $\left.\mathrm{CH}_{3}\right), 2.35\left(\mathrm{~s}, 6 \mathrm{H}, \mathrm{CH}_{3}\right)$, $4.72\left(\mathrm{~s}, 2 \mathrm{H}, \mathrm{CH}_{2}\right), 4.89$ (s, 2H, $\left.\mathrm{CH}_{2}\right), 5.13$ (s, $2 \mathrm{H}, \mathrm{CH}_{2}$ ). Spectrum is in accordance with the previously published [6].

V. Synthesis of sodium (9-hydroxy3,3,8-trimethyl-1,5-dihydro- $[1,3]$ dioxepino $[5,6-c]$ pyridin-6-yl)methanesulfonate (7) starting from (9-acetoxy-3,3,8-trimethyl-1,5-dihydro-[1,3] dioxepino[5,6-c]pyridin-6-yl)methyl acetate (10). Solutions of $100 \mathrm{~g}$ (309 mmol) of bis-acetate $\mathbf{1 0}$ in $400 \mathrm{ml}$ of methanol and $59 \mathrm{~g}$ (464 mmol) of sodium sulfite in $600 \mathrm{ml}$ of distilled water are prepared separately. Solutions are added to the 2 liter round bottom flask equipped with magnetic stirring bar while stirring. The resulting mixture is stirred for $6 \mathrm{~h}$ at room temperature. The solvents are evaporated under vacuum following the same workup procedure as described in synthesis II. The product is dried under vacuum to obtain $57 \mathrm{~g}(57 \%)$ of 7 as white solid; m.p. $197{ }^{\circ} \mathrm{C}$ (decomp.). NMR ${ }^{1} \mathrm{H}(400 \mathrm{MHz}$, DMSO-d $\left.{ }_{6}\right), \delta$, ppm: $1.38\left(\mathrm{~s}, 6 \mathrm{H}, \mathrm{C}\left(\mathrm{CH}_{3}\right)_{2}\right)$, $2.30\left(\mathrm{~s}, 3 \mathrm{H}, \mathrm{CH}_{3}\right), 3.82\left(\mathrm{~s}, 2 \mathrm{H}, \mathrm{CH}_{2} \mathrm{~S}\right), 4.79$ (s, $\left.2 \mathrm{H}, \mathrm{CH}_{2}\right), 4.90\left(\mathrm{~s}, 2 \mathrm{H}, \mathrm{CH}_{2}\right) . \mathrm{NMR}^{13} \mathrm{C}$ $\left\{{ }^{1} \mathrm{H}\right\}(100 \mathrm{MHz}$, DMSO-d 6 ), $\delta$, ppm: 19.28, 23.73, 57.47, 59.11, 60.97, 101.45, 132.07, 134.18, 140.97, 143.25, 146.78. HRMS-ESI: found $[M+H]^{+} 326.0667, \mathrm{C}_{12} \mathrm{H}_{16} \mathrm{NNaO}_{6} \mathrm{~S}$, calculated $[M+H]^{+} 326.0669$.

VI. Synthesis of (5-hydroxy-3,4-bis(hydroxymethyl)-6-methylpyridin-2-yl)methanesulfonic acid (11) starting from 6-(hydroxymethyl)-3,3,8-trimethyl-1,5-dihydro-[1,3] dioxepino[5,6-c] pyridin-9-ol (4). 15 liter glass reactor equipped with anchor-type stirrer, reflux condenser, heating jacket, thermometer and $\mathrm{pH}$-meter is loaded with $1565 \mathrm{~g}$ (6540 mmol) of compound 4 and solution of $1262 \mathrm{~g}$ (9810 mmol) if sodium sulfite in 5.5 liters of distilled water. The reaction mixture is stirred under reflux conditions for $5 \mathrm{~h}$ while maintaining $\mathrm{pH}$ at a range between 8.0 and 9.0 by the addition of small portions of concentrated hydrochloric acid (about $300 \mathrm{ml}$ of acid was used). The reaction is controlled by TCL on silica (eluent $\mathrm{CHCl}_{3}: \mathrm{MeOH}=3: 1$ ) until the spot of starting material completely disappears. Then reaction mixture is cooled down to the room temperature and neutralized with concentrated hydrochloric acid to the $\mathrm{pH}=6.5$ during 30 minutes. The precipitate of by-product is formed and is filtered off. Filtrate is acidified 
to the $\mathrm{pH}=1.0$ with concentrated hydrochloric acid. Acidified mixture is evaporated under vacuum until mushy residue is obtained while absorbing $\mathrm{SO}_{2}$ formed with solution of sodium hydroxide. Residue is heated up until boiling and small portions of water are added until clear solution obtained. After cooling to $0^{\circ} \mathrm{C}$ crystalline precipitate of product $\mathbf{1 1}$ is formed. It is filtered off and washed with $300 \mathrm{ml}$ of ice-cold distilled water. After drying $1120 \mathrm{~g}(65 \%)$ of product $\mathbf{1 1}$ is obtained as off-white to pale yellow solid. Filtrate is evaporated until dryness and extracted with 1 liter of boiling water followed by hot filtration. After cooling this filtrate to $0{ }^{\circ} \mathrm{C}$ second portion $223 \mathrm{~g}$ (13\%) of product 11 was isolated additionally. Overall yield 1343 g (78\%); m.p. $250{ }^{\circ} \mathrm{C}$ (decomp). NMR ${ }^{1} \mathrm{H}\left(400 \mathrm{MHz}, \mathrm{DMSO}-\mathrm{d}_{6}\right), \delta$, ppm: 2.56 (s, $\left.3 \mathrm{H}, \mathrm{CH}_{3}\right), 4.27$ (s, 2H, $\left.\mathrm{CH}_{2} \mathrm{~S}\right), 4.70(\mathrm{~s}, 2 \mathrm{H}$, $\left.\mathrm{CH}_{2}\right), 4.90\left(\mathrm{~s}, 2 \mathrm{H}, \mathrm{CH}_{2}\right) . \mathrm{NMR}{ }^{13} \mathrm{C}\left\{{ }^{1} \mathrm{H}\right\}$ (100 MHz, DMSO-d ${ }_{6}$ ), $\delta$, ppm.: 14.74, 51.57, 55.52, 56.19, 136.44, 138.79, 141.50, 142.95, 151.62. HRMS-ESI: found $[M+H]^{+}$ 264.0537, $\mathrm{C}_{9} \mathrm{H}_{13} \mathrm{NO}_{6} \mathrm{~S}$, calculated $[M+H]^{+}$ 264.0536.

\section{Results and discussion}

The starting point of our research was synthetic method described below in Scheme 1.

As can be seen overall yield is slightly greater than 18\%. Moreover, two steps (c and d) require column chromatography. In case of intermediate $\mathbf{5}$ chromatography is needed to separate ester by the benzyl group from the desired compound. This also explains poor yield at this step.

As substance $\mathbf{3}$ has hydroxymethyl group in the para- position in relation to the phenol $\mathrm{OH}$. It makes possible to investigate the possibility of functionalization of this scaffold via meta- quinon methide
VI. Synthesis of sodium (5-hydroxy3,4-bis(hydroxymethyl)-6-methylpyridin2-yl)methanesulfonate (1) starting from (5-hydroxy-3,4-bis(hydroxymethyl)6-methylpyridin-2-yl)methanesulfonic acid (11). 15 liter glass reactor equipped with anchor-type stirrer is loaded with $1343 \mathrm{~g}$ (5100 mmol) of compound 11 and solution of $204 \mathrm{~g}$ (5100 mmol) of sodium hydroxide in 2.5 liters of water. Mixture is stirred at room temperature during 6 minutes until clear solution is obtained. Then 12 liters of isopropyl alcohol is added and white precipitate is formed immediately. Solid is filtered off, washed with twice with 1 liter of isopropyl alcohol and dried to obtain $1427 \mathrm{~g}$ (98\%) of product $\mathbf{1}$ as a white solid with purity $>99.5 \%$ (HPLC); m.p. $265{ }^{\circ} \mathrm{C}$ (decomp.). NMR ${ }^{1} \mathrm{H}(400 \mathrm{MHz}, \mathrm{DMSO}-$ $\mathrm{d}_{6}$ ), $\delta$, ppm: 2.31 (s, 3H, $\left.\mathrm{CH}_{3}\right) ; 4.04$ (s, 2H, $\left.\mathrm{CH}_{2}\right), 4.51\left(\mathrm{~d},{ }^{3} \mathrm{~J}_{\mathrm{HH}}=6.3 \mathrm{~Hz}, 2 \mathrm{H}, \mathrm{CH}_{2}\right) ; 4.78$ $\left(\mathrm{s}, 2 \mathrm{H}, \mathrm{CH}_{2}\right) ; 5.17\left(\mathrm{t},{ }^{3} \mathrm{~J}_{\mathrm{HH}}=6.3 \mathrm{~Hz}, 1 \mathrm{H}\right.$, $\mathrm{OH}) . \mathrm{NMR}^{13} \mathrm{C}\{1 \mathrm{H}\}\left(100 \mathrm{MHz}, \mathrm{DMSO}-\mathrm{d}_{6}\right)$, $\delta$, ppm: 19.33, 56.80, 57.16, 57.21, 132.07, 132.74, 143.31, 145.04, 148.94. HRMS-ESI: found $[M+H]^{+} 286.0354, \mathrm{C}_{9} \mathrm{H}_{12} \mathrm{NNaO}_{6} \mathrm{~S}$, calculated $[M+H]^{+} 286.0356$.

intermediate. The reactivity of orto- and para-quinon methides intermediates is well studied in non-heterocyclic aromatic structures $[7,8]$. But we can barely find any data on its heterocyclic analogs.

Acetyl esters $\mathbf{8}$ and $\mathbf{9}$ are among usual quinone methide precursors $[9,10]$ (Fig. 2).

In this connection bis-acetic ester 8 that was synthesized earlier in our research group [6] was a good starting point for the optimization of synthetic route. It has straightforward synthesis with no need of chromatographic purification. It was shown that use of acetyl chloride in- 


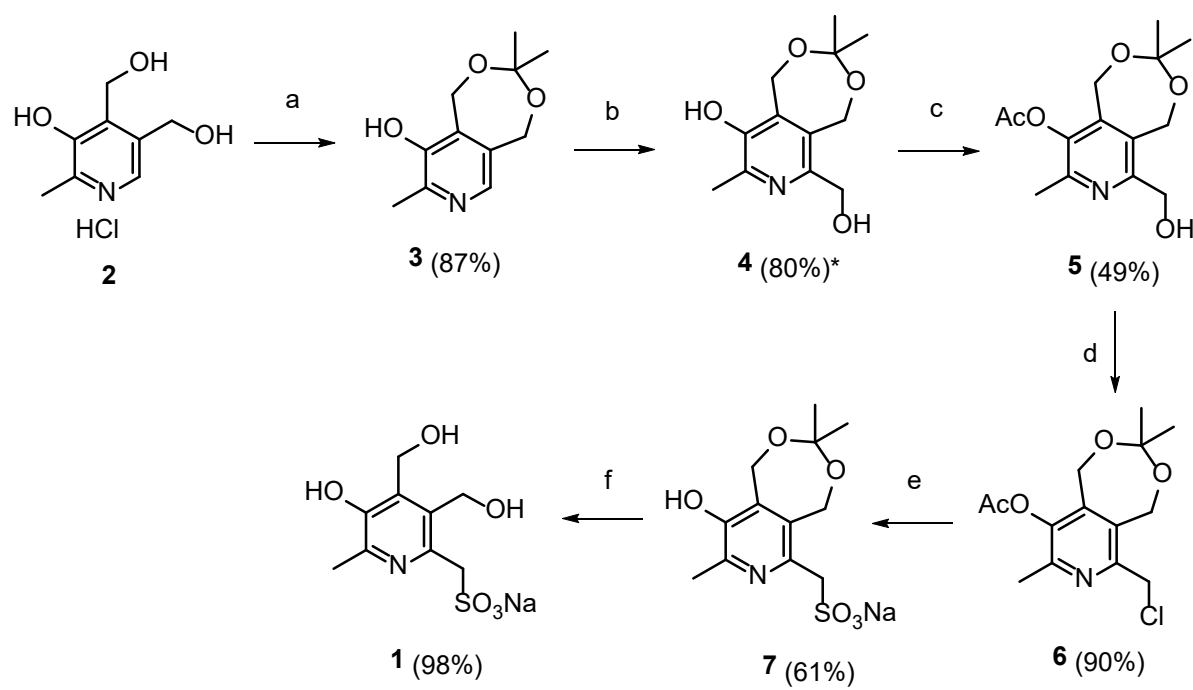

Scheme 1. Reagents and conditions: (a) $\left(\mathrm{CH}_{3}\right)_{2} \mathrm{CO}, \mathrm{HCl}, 0^{\circ} \mathrm{C}, 12 \mathrm{~h} \mathrm{[3]}$; (b) $\mathrm{CH}_{2} \mathrm{O}, \mathrm{NaOH}, \mathrm{H}_{2} \mathrm{O}$, $70{ }^{\circ} \mathrm{C}, 60 \mathrm{~h} \mathrm{[4]}$; (c) $\mathrm{Ac}_{2} \mathrm{O}, \mathrm{Et}_{3} \mathrm{~N}, \mathrm{CH}_{2} \mathrm{Cl}_{2}$, r.t., $30 \mathrm{~h} \mathrm{[5];} \mathrm{(d)} \mathrm{MsCl}, \mathrm{Et}_{3} \mathrm{~N}, \mathrm{CHCl}_{3}, 0{ }^{\circ} \mathrm{C}$ to r.t., $10 \mathrm{~h} \mathrm{[5];}$

(e) $\mathrm{Na}_{2} \mathrm{SO}_{3}, \mathrm{TBAB}, \mathrm{CH}_{2} \mathrm{Cl}_{2} / \mathrm{H}_{2} \mathrm{O}$, r.t., $10 \mathrm{~h}$; (f) $\mathrm{HCl}, \mathrm{H}_{2} \mathrm{O}$, r.t., $1 \mathrm{~h}$

* - yield according to non-optimized method [4]

stead of acetic anhydride as an acylating agent in synthesis of $\mathbf{8}$ dramatically reduces the reaction time from 30 hours [6] to only 0.5 hour with no need of refluxing conditions (Scheme 2).

It was shown that bis-acetyl ester $\mathbf{1 0}$ can react with primary and secondary amines in alcohol media [11]. An attempt was made to investigate reactivity of $\mathbf{1 0}$ toward sulfur-containing nucleophile such as sodium sulfite. Very poor solubility of sodium sulfite in almost any organic media including alcohols became the main barrier for this reaction. Usual methods like two-phase reaction system $\left(\mathrm{H}_{2} \mathrm{O} / \mathrm{CH}_{2} \mathrm{Cl}_{2}\right)$ with phase transfer catalyst gave very low yields even after prolonged reaction time. However, it was an indication of the principal possibility of such a reaction. The best results (57\% yield of 6) were achieved using mixed solvent water/MeOH in 3:2 ratio by the volume. In this mixture both components of the reaction have significant solubility. Replacement of $\mathrm{MeOH}$ with $\mathrm{EtOH}$ or any other alcohol significantly reduces the solu- bility of sodium sulfite slowing the reaction and reducing the yield. The development of this synthetic step not only reduces total amount of steps, it allows to avoid chromatographic purification of intermediates $\mathbf{5}$ and $\mathbf{6}$ which are no longer needed. With this implementation total yield was increased from $18 \%$ to $38 \%$ with no principal limitation for the scaling-up.

Another optimization was made during the scaling-up of the process. Original method of the synthesis of $\mathbf{4}$ includes extraction with ethanol during the workup. After the evaporation of ethanol 4 is obtained as white solid with significant solu-

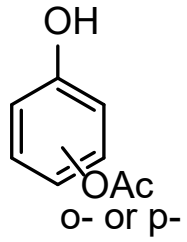

8

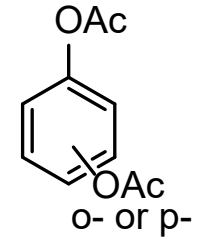

9
Fig. 2. Structures of acetyl esters 8 and $\mathbf{9}$ as quinone methide precursors 


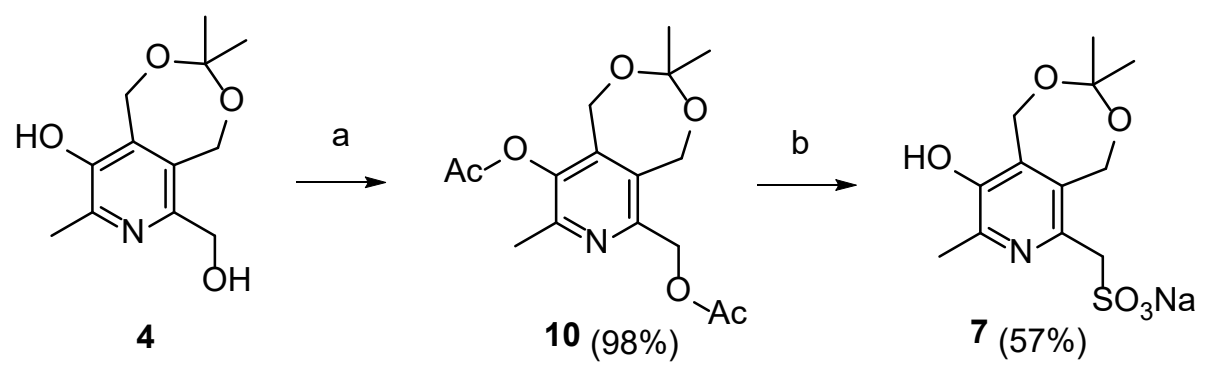

Scheme 2. Reagents and conditions:

(a) $\mathrm{AcCl}, \mathrm{NEt}_{3}, \mathrm{CH}_{2} \mathrm{Cl}_{2}$, r.t. 0.5 h; (b) $\mathrm{Na}_{2} \mathrm{SO}_{3}, \mathrm{H}_{2} \mathrm{O} / \mathrm{MeOH}$, r.t., 6 h

bility in water and melting point of 161$163{ }^{\circ} \mathrm{C}$. However, the crystalline solid precipitates from water solutions of $\mathbf{4}$ after long standing. It was found to have similar NMR spectra as $\mathbf{4}$ and melting point of $182-183^{\circ} \mathrm{C}$ which indicates another crystalline form of the same compound. This finding allows to alter the workup procedure of the synthesis of $\mathbf{4}$ which consists in seed induces precipitation of product from the neutralized mother liquor. This alteration not only simplified the procedure but also improved the yield up to $94 \%$ at this step due to more complete precipitation. The use of freshly distilled formaldehyde solution and use of more concentrated reaction mixture (less solvent) allows to dramatically reduce the reaction time from 60 to 6 hours.

In some examples o- and p- hydroxymethylphenols may play a role of the quinon methide precursors. This examples are usually limited to the reaction with C-nucleophiles like base-activated 2-nitropropane [12] or potassium cyanide [13]. Reactions of pyridoxine with different alcohols are described yielding corresponding 4 ' - esters [14]. The latter do not have much practical significance due to very long reaction time (about 96 hours).

The original work [15] and its modern reiteration [16] has evidence of the possibility of direct reaction between p-hy- droxymethylphenol and sodium hydrosulfite. This reaction has a good yield and requires refluxing in the water media for only 8 hours. Possible application of this method to the direct synthesis of compound 7 starting from 4 allows reducing the total amount of steps.

It was found that reaction of $\mathbf{4}$ with sodium hydrosulfite is not possible as $\mathrm{pH}$ of the reaction mixture is slightly acidic $(\mathrm{pH}=4-5)$ and it is enough the remove the dimethylketal protecting group. The replacement of hydrosulfite with sulfite gave the first results as it makes possible to achieve the partial conversion of 4 to 7 . The conversion was not complete even after prolonged refluxing. Usually it reaches $60-70 \%$ in 6 hours and does not change after. This process is believed to be reversible (Fig. 3) and the conversion observed corresponds to the equilibrium. The changes of $\mathrm{pH}$ of the reaction mixture were observed during the process: from $\mathrm{pH}=11$ at the start to $\mathrm{pH}=13.5$ at the equilibrium. The addition of small amounts of acid to control $\mathrm{pH}$ makes it possible to reach complete conversion. It was found that optimal $\mathrm{pH}$ for the reaction is in range between 8.0 and 9.0. Under this $\mathrm{pH}$ controlled conditions reaction completes in 5 hours of refluxing.

It was found to be unpractical to isolate compound 7 before the deprotection 
step as it requires extraction with huge amount of isopropyl alcohol. Deprotection step may be done by the acidification of the reaction mixture from the previous step with the isolation of sulfonic acid 11 as it has limited solubility in cold water. The overall optimized synthesis of $\mathbf{1}$ is shown in Scheme 3.<smiles>Cc1nc(CO)c2c(c1O)COC(C)(C)OC2</smiles>

4

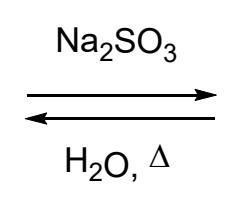

a<smiles>Cc1ncc(CO)c(CO)c1O</smiles>

2

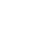<smiles>Cc1ncc2c(c1O)COC(C)(C)OC2</smiles>

$3(87 \%)$<smiles>Cc1nc(CS(=O)(=O)O[Na])c2c(c1O)COC(C)(C)OC2</smiles>

7

Fig. 3. Preparation of compound 7 from 4 with sodium sulfite<smiles>Cc1nc(CS(=O)(=O)O[Na])c(CO)c(CO)c1O</smiles><smiles>Cc1nc(CO)c2c(c1O)COC(C)(C)OC2</smiles>
c, d<smiles>Cc1nc(CS(=O)(=O)O)c(CO)c(CO)c1O</smiles>

$11(78 \%)$

Scheme 3. Reagents and conditions: (a) $\left(\mathrm{CH}_{3}\right)_{2} \mathrm{CO}, \mathrm{HCl}, 0{ }^{\circ} \mathrm{C}, 12 \mathrm{~h}$ [3];

(b) $\mathrm{CH}_{2} \mathrm{O}, \mathrm{NaOH}, \mathrm{H}_{2} \mathrm{O}, 70^{\circ} \mathrm{C}, 6 \mathrm{~h}$; (c) $\mathrm{Na}_{2} \mathrm{SO}_{3}, \mathrm{H}_{2} \mathrm{O}, \mathrm{pH}=8.0-9.0$, reflux, $5 \mathrm{~h}$;

(d) $\mathrm{HCl}, \mathrm{pH}=1.0,0.5$ h, r.t.; (e) $\mathrm{NaOH}, \mathrm{H}_{2} \mathrm{O}$, r.t., $0.1 \mathrm{~h}$

* - yield according to optimized method of synthesis (see experimental) 


\section{Conclusions}

Thus, the total yield of the final method of synthesis of the antiepileptic drug candidate Sumepirin 1 starting prom pyridoxine hydrochloride was increased from $18 \%$ to $62.5 \%$. As the result of optimization the amount of steps was reduced from six to four. It is also important that this method is environment-friendly: at first step reagent (acetone) is used as a solvent

and any other step is carried out in water media; good level of atom economy was achieved due to elimination of chloride and acetyl protecting or leaving groups from the synthetic route. Unfortunately, it does not seem to be possible not to use the dimethylketal protecting group because $\mathrm{OH}$ groups in 4' and 6' positions of pyridoxine ring have very similar reactivity.

\section{Acknowledgements}

This work was supported by subsidy allocated to Kazan Federal University for the state assignment in the sphere of scientific activities (project number 0671-2020-0053).

\section{References}

1. Janmohamed M, Brodie MJ, Kwan P. Pharmacoresistance - Epidemiology, mechanisms, and impact on epilepsy treatment. Neuropharmacology. 2020;168:107790 doi:10.1016/j.neuropharm.2019.107790

2. Štuhec M. Optimization of antiepileptic drug pharmacotherapy related to adverse drug effects: How to approach . Farm Vestn. 2015;66(1):28-34.

3. Korytnyk W. A seven-membered cyclic ketal of pyridoxol. J Org Chem. 1962;27(10):3724-6.

4. Shtyrlin NV, Strel'Nik AD, Sysoeva LP, Lodochnikova OA, Klimovitskii EN, Shtyrlin YG. New synthetic method for 2,3,4-tris(hydroxymethyl)-6-methylpyridin-5-ol. Russ J Org Chem. 2009;45(8):1266-8.

doi:10.1134/S1070428009080314

5. Pugachev MV, Shtyrlin NV, Sysoeva LP, Nikitina EV, Abdullin TI, Iksanova AG, Ilaeva AA, Berdnikov EA, Musin RZ, Shtyrlin YG. Synthesis and antibacterial activity of novel phosphonium salts on the basis of pyridoxine. Bioorg Med Chem. 2013;21(14):4388-95.

doi:10.1016/j.bmc.2013.04.051

6. Shtyrlin NV, Dobrynin AB, Madzhidov TI, Pugachev MV, Sysoeva LP, Musin RZ, Litvinov IA, Klimovitskii EN, Shtyrlin YG. Experimental and theoretical study on 6-substituted pyridoxine derivatives. Synthesis of Cyclic 2,4,5,6-Tetrakis-(hydroxymethyl) pyridin-3-ol Acetonides. Russ J Org Chem. 2011;47(1):100-8.

doi:10.1134/S107042801101012X

7. Lima CGS, Pauli FP, Costa DCS, de Souza AS, Forezi LSM, Ferreira VF, Da Silva F. C. para-Quinone Methides as Acceptors in 1,6-Nucleophilic Conjugate Addition Reactions for the Synthesis of Structurally Diverse Molecules. Eur J Org Chem. 2020;2020(18):2650-92.

doi:10.1002/ejoc.201901796 
8. Mukhopadhyay S, Gharui C, Pan SC. Applications of Bifunctional Organocatalysts on ortho-Quinone Methides. Asian J Org Chem. 2019;8(11):1970-84.

doi:10.1002/ajoc.201900466

9. Loubinoux B, Miazimbakana J, Gerardin P. Reactivity of new precursors of quinone methides. Tetrahedron Lett. 1989;30(15):1939-42.

doi:10.1016/S0040-4039(00)99619-9

10. Sanner MA, Stansberry M, Weigelt C, Michne WF. Quinone methide from 4-hydroxybenzyl alcohol diacetate: (P-acetoxy)benzylation of $\beta$-dicarbonyls. Tetrahedron Lett. 1992;33(37):5287-90.

doi:10.1016/S0040-4039(00)79074-5

11. Khaziev R, Shtyrlin N, Pavelyev R, Nigmatullin R, Gabbasova R, Grishaev D, Shtro A, Galochkina A, Nikolaeva Y, Vinogradova T, Manicheva O, Dogonadze M, Gnezdilov O, Sokolovich E, Yablonskiy P, Balakin K, Shtyrlin Y. Synthesis and antimicrobial activity of adamantyl substituted pyridoxine derivatives. Lett Drug Des Discov. 2019;16(12):1360-9.

doi:10.2174/1570180816666190911150705

12. Finley DR, Bell MG, Borel AG, Bloomquist WE, Cohen ML, Heiman ML, Kriauciunas A, Matthews DP, Miles T, Neel DA, Rito CJ, Sall DJ, Shuker AJ, Stephens TW, Tinsley FC, Winter MA, Jesudason CD. Potent benzimidazolone based human $\beta^{3}$-adrenergic receptor agonists. Bioorg Med Chem Lett. 2006;16(21):5691-4. doi:10.1016/j.bmcl.2006.08.010

13. Murai M, Okamoto K, Miki K, Ohe K. Palladium-catalyzed three-component coupling reactions of 2-(cyanomethyl)phenol, aryl halides, and carbon monoxide. Tetrahedron. 2015;71(26):4432-7. doi:10.1016/j.tet.2015.04.049

14. Yazarians JA, Jiménez BL, Boyce GR. A regioselective etherification of pyridoxine via an ortho-pyridinone methide intermediate. Tetrahedron Lett. 2017;58(23):2258-60. doi:10.1016/j.tetlet.2017.04.082

15. Shearing EA, Smiles S. Derivatives of o-hydroxybenzylsulphonic acid. J Chem Soc. $1937 ; 1348-51$.

doi:10.1039/jr9370001348

16. Jankowski P, Poterała M, Lindahl N, Wieczorek W, Johansson P. Chemically soft solid electrolyte interphase forming additives for lithium-ion batteries. J Mater Chem A. 2018;6(45):22609-18. doi:10.1039/c8ta07936f 